\title{
Synthesis and Properties of Fluorine-Containing Poly(arylenemethylene)s as New Heat Resistant Denatured Phenolic Resins
}

\author{
By Tadamasa NEMOTO, Gen-ichi KONISHI, ${ }^{*}$ Takayuki ARAI, and Toshikazu TAKATA
}

We report the synthesis of fluorine-containing poly(arylenemethylene)s as a new heat-resistant denatured phenolic resin by addition-condensation or Friedel-Crafts polymerization. In the case of polymerization of 2,2-bis(4-methoxyphenyl)hexafluoropropane (1a) with an equimolar amount of formaldehyde, the polymerization proceeded homogeneously to give the polymer 2a $\left(M_{\mathrm{n}} 8,200, M_{\mathrm{w}} / M_{\mathrm{n}} 2.1\right)$ in $71 \%$ yield. The FT-IR, ${ }^{1} \mathrm{H}$ NMR and ${ }^{13} \mathrm{C}$ NMR spectra of $2 \mathrm{a}$ revealed that it had arylene-methylene units on the polymer backbone. The polymerizations of 3-(trifluoromethoxy)benzyl bromide (1b) or 4(trifluoromethoxy)benzyl bromide (1c) via the Friedel-Crafts polymerization using aluminum chloride as a catalyst produced the polymer $\mathbf{2 b}$ and $\mathbf{2 c}$ in $38 \%$ and $16 \%$ yield, respectively. From the TGA, the temperatures at $10 \%$ loss in weight ( $\left.T_{10}\right)$ of $\mathbf{2 a}$ and $2 \mathrm{c}$ were found to be 425 and $298^{\circ} \mathrm{C}$, respectively. As compared to the non-fluorinated poly(arylenemethylene) derived from 2,2-bis(4-methoxyphenyl)propane-formaldehyde polymer $(\mathbf{2 d})\left(T_{10}=397^{\circ} \mathrm{C}\right), \mathbf{2 a}$ showed high thermostability in terms of the temperature of $T_{10}$. The results indicated that the thermal stability of poly(arylenemethylene)s was enhanced by the introduction of fluorine moieties in the polymer.

KEY WORDS: Phenolic Resin / Novolac / Addition-Condensation / Friedel-Crafts Polymerization / Fluorine-Containing Polymer /

Heat Resistant Material /

Phenolic resins are one of the most important thermosetting resins and have been industrially utilized as cures, adhesives, photoresists, and polymer composites. ${ }^{1,2}$ From the material viewpoint, the phenolic hydroxyl group of the resin plays an important role in processing, curing, polymer reactions, and adhesion. On the other hand, the phenolic resin's significant characters such as heat stability and mechanical properties have been derived from a rigid-rod-like polymer backbone "poly(phenylenemethylene)." ${ }^{3}$ However, there exists limited knowledge regarding the designing of a new functional phenolic resin from natural materials.

Recently, we have suggested the design of a new highperformance aromatic polymer; in particular, a new category of phenolic resins were prepared from an alkoxylated phenol or its derivatives such as anisole, alkoxybenzene, polyalkylbenzenes, and naphthalene derivatives via a method similar to the acidcatalyzed phenol-formaldehyde condensation. ${ }^{3-5}$ The obtained phenolic resins were similar to denatured novolac resins and demonstrated good solubility in organic solvents and high heat resistance as compared with the conventional phenolic novolacs. It is very important to explore the chemistry of these novel novolacs toward other electron-rich aromatic compounds. We now focus on fluorinated phenol derivatives.

Fluorine-containing polymers ${ }^{6}$ are known to be highly heat resistant, chemical tolerable, and water/oil repellent materials that are often utilized as coating materials, kitchenware, etc. The $\mathrm{C}-\mathrm{F}$ bond has an extremely high resistance to external stimuli, and as a result, is not polarized. ${ }^{7}$ Fluorine-containing polymers are also used as optical and electronic industrial materials due to their low-refractive index and low permittivity. Therefore, the introduction of a fluorinated moiety to the alkoxylated phenolic resins will reveal the unexplored aspects of the resins; further, the obtained polymers are expected to demonstrate higher heat resistance and water repellency and can form polymer composites with other fluorinated polymers.

In this paper, we report the preparation of two new types of fluorinated novolacs by the acid-catalyzed addition-condensation of 2,2-bis(4-methoxyphenyl)hexafluoropropane (1a) as the fluorine-containing phenol derivatives with formaldehyde, or by the Friedel-Crafts polymerization of trifluoromethoxysubstituted benzyl bromide $(\mathbf{1 b}, \mathbf{1 c})$. Further, the thermal and solution properties and water repellency of the obtained polymers are also discussed.

\section{EXPERIMENTAL}

\section{Instruments}

All the ${ }^{1} \mathrm{H}$ NMR and ${ }^{13} \mathrm{C}$ NMR spectra were obtained in $\mathrm{CDCl}_{3}$ and recorded by using a 400-MHz JEOL LNM-EX400 with tetramethylsilane (TMS) as the internal standard. The FTIR spectra were recorded using a JASCO FT-IR 460 plus spectrometer. Gel permeation chromatography (GPC) was performed either by using a JASCO UV-2075 detector and a JASCO RI-2031 detector (TOSOH TSKgel G3000H $\mathrm{HL}_{\mathrm{XL}}$ or TSKgel $\mathrm{G} 4000 \mathrm{H}_{\mathrm{XL}}$ column) using tetrahydrofuran (THF) as the eluent after calibration with polystyrene standards or by a

Department of Organic \& Polymeric Materials, Graduate School of Science \& Engineering, Tokyo Institute of Technology, 2-12-1-H-134, Ookayama, Meguro-ku, Tokyo 152-8552, Japan

*To whom correspondence should be addressed (Tel: +81-3-5734-2321, Fax: +81-3-5734-2888, E-mail: konishi.g.aa@m.titech.ac.jp). 


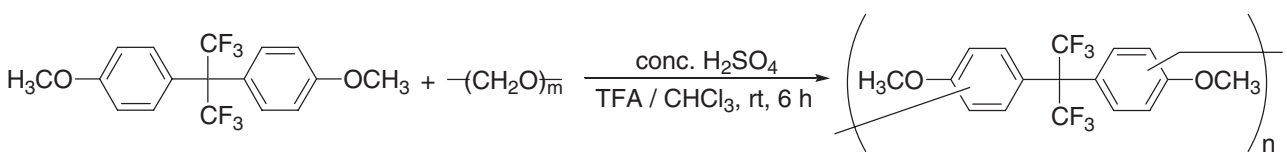

Scheme 1. Polymerization of 2,2-bis(4-methoxyphenyl)hexafluoropropane (1a) with formaldehyde.

JASCO UV-1570 detector and a JASCO RI-1530 detector (TOSOH TSKgel GMH $\mathrm{XL}_{\mathrm{L}}$ column and TSKgel G2000H $\mathrm{XL}$ column) using chloroform as the eluent after calibration with polystyrene standards. Thermogravimetric analysis (TGA) was performed using a SII TG/DTA 6200 with a heating rate of $10{ }^{\circ} \mathrm{C} / \mathrm{min}$ under a nitrogen atmosphere. The solution property of the polymer in a dilute THF solution was examined by a SEC-VISC-RALLS system (Viscotek). The sample with a higher molecular weight fraction for the solution property was separated by using HPLC (LC-9204, JAI). Contact angle measurements were conducted on a KRÜSS DSA100 instrument using deionized water as a probe liquid.

\section{Materials}

Unless otherwise noted, all reagents and chemicals were purchased from TCI, and used without further purifications. Paraformaldehyde (95\%) (Nacalai Tesque), 3-(Trifluoromethoxy)benzyl bromide (1b) (Fluorochem), and 4-(Trifluoromethoxy)benzyl bromide (1c) (Alfa Aesar) were purchased. 2,2Bis(4-methoxyphenyl)hexafluoropropane (1a) was prepared by Williamson ether synthesis.

Addition-condensation of 2,2-Bis(4-methoxyphenyl)hexafluoropropane (1a) with Formaldehyde

To a mixture of $1 \mathbf{a}(0.36 \mathrm{~g}, 1.0 \mathrm{mmol})$ and paraformaldehyde $(0.030 \mathrm{~g}, 1.0 \mathrm{mmol}$ as a formaldehyde unit) were added trifluoroacetic acid $(2 \mathrm{~mL})$ and chloroform $(3 \mathrm{~mL})$ at room temperature (Scheme 1). After stirring for a few minutes, $0.2 \mathrm{~mL}$ of conc. sulfuric acid was added dropwise to the mixture at $0{ }^{\circ} \mathrm{C}$. The resulting mixture was stirred at room temperature for $6 \mathrm{~h}$, and then poured into methanol $(100 \mathrm{~mL})$ and the crude product was collected. The crude product was dissolved in $\mathrm{CHCl}_{3}$ and reprecipitated into methanol to give the polymer (2a) in $71 \%$ yield.

2a: ${ }^{1} \mathrm{H}$ NMR $\left(400 \mathrm{MHz}, \delta(\mathrm{ppm}), \mathrm{CDCl}_{3}\right)$ : 7.2-6.4 (Ar-H), 4.1-3.7 $\left(-\mathrm{CH}_{2}-\right), 3.7-3.2\left(-\mathrm{OCH}_{3}\right) ;{ }^{13} \mathrm{C} \mathrm{NMR}(100 \mathrm{MHz}, \delta$ (ppm), $\mathrm{CDCl}_{3}$ ): 159.8-159.4, 158.0-156.0 (aromatic $C$ attached to a methoxy group), 133.6-119.7 (aromatic $C$ without a methoxy group), 113.5-113.1, 110.2-108.6 (C-CF $)$, 64.462.9, 60.9-60.1 $\left(\mathrm{CF}_{3}-\mathrm{C}-\mathrm{CF}_{3}\right), 55.5-54.4\left(\mathrm{Ar}-\mathrm{OCH}_{3}\right), 32.1-$ 29.8 ( $\mathrm{Ar}-\mathrm{CH}_{2}-\mathrm{Ar}$ ); FT-IR $\left(\mathrm{KBr}, \mathrm{cm}^{-1}\right)$ : 3080 (aromatic C-H stretch), 2961 (aliphatic C-H stretch), 1615 (aromatic C-C stretch), 1039 (C-F stretch).

Polymerization of 3-(trifluoromethoxy)benzyl Bromide (1b)

To a solution of $\mathbf{1 b}(0.26 \mathrm{~g}, 1.0 \mathrm{mmol})$ in 1,2-dichloroethane $(3 \mathrm{~mL})$ was added aluminum chloride $(0.27 \mathrm{~g}, 2.0 \mathrm{mmol})$ at $0{ }^{\circ} \mathrm{C}$ (Scheme 2). After stirring at $50{ }^{\circ} \mathrm{C}$ for $14 \mathrm{~h}$, the reaction mixture was cooled to room temperature, and then cold water

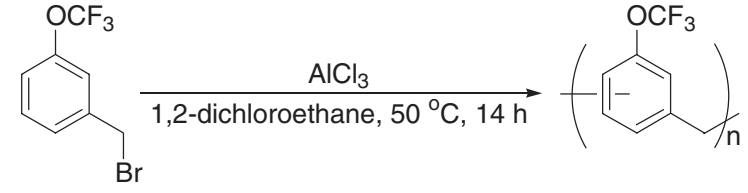

Scheme 2. Polymerization of (3-trifluoromethoxy)benzyl bromide (1b) via a Friedel-Crafts alkylation.

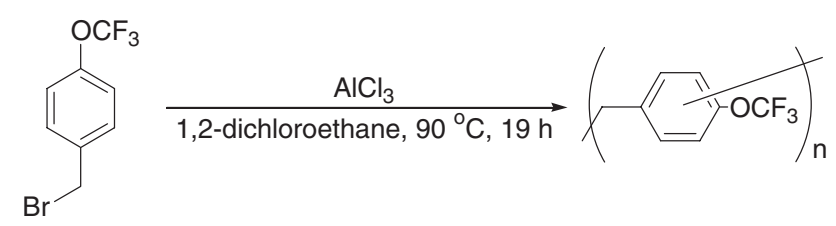

Scheme 3. Polymerization of (4-trifluoromethoxy)benzyl bromide (1c) via a Friedel-Crafts alkylation.

was added to the mixture. The crude product was extracted with $\mathrm{CHCl}_{3}$, and the organic phase was washed by saturated brine and water. After drying over $\mathrm{Na}_{2} \mathrm{SO}_{4}$, the organic phase was evaporated to $5 \mathrm{~mL}$ volume, and then poured into methanol $(100 \mathrm{~mL})$ to give the product $(\mathbf{2 b})$ in $38 \%$ yield.

2b: ${ }^{1} \mathrm{H}$ NMR $\left(400 \mathrm{MHz}, \delta\right.$ (ppm), $\left.\mathrm{CDCl}_{3}\right)$ : 8.4-7.7, 7.2-6.5 $(\mathrm{Ar}-\mathrm{H}), 4.7-3.5\left(-\mathrm{CH}_{2}-\right)$; FT-IR $\left(\mathrm{KBr}, \mathrm{cm}^{-1}\right)$ : 3061 (aromatic C-H stretch), 2957 (aliphatic C-H stretch), 1043 (C-F stretch).

\section{Polymerization of 4-(trifluoromethoxy)benzyl Bromide (1c) in Solution}

To a solution of $1 \mathrm{c}(0.51 \mathrm{~g}, 2.0 \mathrm{mmol})$ in 1,2-dichloroethane $(5 \mathrm{~mL})$ was added aluminum chloride $(0.53 \mathrm{~g}, 4.0 \mathrm{mmol})$ at $0{ }^{\circ} \mathrm{C}$ (Scheme 3). After stirring at $90^{\circ} \mathrm{C}$ for $19 \mathrm{~h}$, the reaction mixture was cooled to room temperature, and then cold water was added to the mixture. The crude polymer was extracted with $\mathrm{CHCl}_{3}$, and the organic phase was washed by a saturated brine and water. After drying over $\mathrm{Na}_{2} \mathrm{SO}_{4}$, the organic phase was evaporated to $5 \mathrm{~mL}$ volume, and then poured into methanol $(100 \mathrm{~mL})$ to give the polymer in $67 \%$ yield.

\section{Bulk Polymerization of 4-(trifluoromethoxy)benzyl Bro- mide (1c)}

To a $10 \mathrm{~mL}$ round bottom flask, aluminum chloride $(0.79 \mathrm{~g}$, $6.0 \mathrm{mmol})$ and $1 \mathrm{c}(0.78 \mathrm{~g}, 3.1 \mathrm{mmol})$ were added. After stirring for $1 \mathrm{~d}$ at room temperature, 1,2-dichloroethane $(5 \mathrm{~mL})$ and water $(5 \mathrm{~mL})$ were added to the reaction mixture. The cured product was extracted with $\mathrm{CHCl}_{3}$, and the organic phase was washed by saturated brine and water. After drying over $\mathrm{Na}_{2} \mathrm{SO}_{4}$, the organic phase was evaporated to $5 \mathrm{~mL}$ volume, and then poured into methanol $(100 \mathrm{~mL})$ to give the polymer (2c) in $16 \%$ yield. 


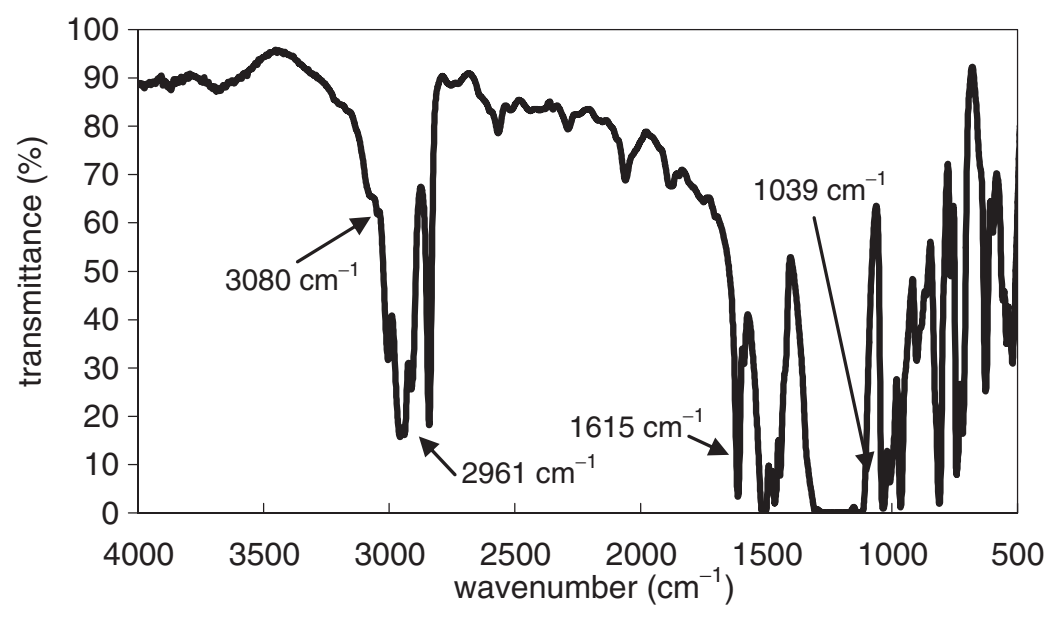

Figure 1. FT-IR spectrum of 2 a.

2c: ${ }^{1} \mathrm{H}$ NMR $\left(400 \mathrm{MHz}, \delta(\mathrm{ppm}), \mathrm{CDCl}_{3}\right)$ : 7.8-7.6, 7.2-6.5 (Ar$H), 4.1-3.5\left(-\mathrm{CH}_{2}-\right)$; ${ }^{13} \mathrm{C} \mathrm{NMR}\left(100 \mathrm{MHz}, \delta(\mathrm{ppm}), \mathrm{CDCl}_{3}\right)$ : 146.8-145.3 (aromatic $C$ attached to a methoxy group), 139.8118.5 (aromatic $C$ without a methoxy group), 130.4-129.2 (Ar$\mathrm{OCF}_{3}$ ), 38.7-34.2 (Ar-CH$\left.-\mathrm{Ar}\right)$; FT-IR $\left(\mathrm{KBr}, \mathrm{cm}^{-1}\right): 3040$ (aromatic C-H stretching vibration), 2924 (aliphatic C-H stretching vibration), 1060 (C-F stretching vibration).

\section{RESULTS AND DISCUSSION}

Addition-condensation of 2,2-Bis(4-methoxyphenyl)hexafluoropropane (1a) with Formaldehyde

The addition-condensation of 2,2-bis(4-methoxyphenyl)hexafluoropropane (1a) with formaldehyde was performed according to Scheme 1 (the typical method is cited in the experimental section). An organosoluble polymer (2a) was obtained in good yield. The structure of $\mathbf{2 a}$ was confirmed from ${ }^{1} \mathrm{H}$ NMR, ${ }^{13} \mathrm{C}$ NMR, and FT-IR spectra. The FT-IR spectrum of $\mathbf{2 a}$ displayed the peaks derived from a benzene ring $\left(3080 \mathrm{~cm}^{-1}\right)$, a methylene unit $\left(2961 \mathrm{~cm}^{-1}\right)$, and a C-F bond $\left(1039 \mathrm{~cm}^{-1}\right)$ (Figure 1). The presence of aromatic and methylene bridge protons in 2a was confirmed from the peaks at 7.2-6.4 ppm and 4.1-3.7 ppm, respectively, in the ${ }^{1} \mathrm{H}$ NMR spectrum. The ${ }^{13} \mathrm{C}$ NMR spectrum of 2 a revealed the presence of methylene units (32.1-29.8 ppm), a substituted carbon attached to a methoxy group (159.8-159.4, 158.0-156.5 ppm), and other carbon groups (133.6-119.7 ppm) on the benzene rings (Figure 3 ) according to our previous report. ${ }^{5 \mathrm{a}}$ The results indicated that the product 2a comprised only arylene-methylene units, as shown in Scheme 1.

The polymer structure of $2 \mathbf{a}$ can be discussed in detail on the basis of the ${ }^{1} \mathrm{H}$ and ${ }^{13} \mathrm{C}$ NMR spectra. The peaks derived from the aromatic protons $\mathrm{H}_{\mathrm{a}}$ and $\mathrm{H}_{\mathrm{b}}, \mathrm{H}_{\mathrm{c}}$, and $\mathrm{H}_{\mathrm{d}}$ of $\mathbf{2 a}$ appeared at 7.2-6.9, 6.9-6.7, and 6.7-6.4 ppm, respectively (Figure 2). The ${ }^{13} \mathrm{C}$ NMR spectrum displayed the peaks derived from the carbon attached to the methoxy group on a benzene ring (Figure 3). The peaks indicated that the benzene rings had three types of benzene moieties, i.e., non-, mono-, and di- substituted by methylene units. These results suggested that $\mathbf{2 a}$ had a branched structure, as shown in Figure 4. However, it was difficult to calculate the abundance ratio of the linear structure to the branched structure from the integral ratio of each peak based on the ${ }^{1} \mathrm{H}$ NMR spectrum because the peaks derived from the aromatic protons overlapped each other. The number-average molecular weight $\left(M_{\mathrm{n}}\right)$ and polydispersity index $\left(M_{\mathrm{w}} / M_{\mathrm{n}}\right)$ of $\mathbf{2 a}$ were estimated to be 8200 and 2.1, respectively, by GPC.

The results of the polymerization under various conditions are summarized in Table I. When the addition-condensations were performed without any acid catalysts, either the polymerizations did not proceed or the isolated products had a low $M_{\mathrm{n}}$ (Table I, runs 1-4). The product obtained in run 5 had a lower molecular weight as compared to that obtained in run 6 . This result indicated that chloroform served as a good solvent for the products. When the addition-condensation of $\mathbf{1 a}$ with formaldehyde was carried out under concentrated conditions, the products formed an insoluble gel in the reaction mixtures (Table I, runs 7-8). This implied that the number of polymer backbones had increased owing to cross-linking. When the feed ratio of 1a to formaldehyde was changed to 1:1.5, the yield of the polymer increased, and at a ratio of 1:2 (Table I, runs 9-10), polymers with high number-average molecular weights and broad polydispersity indexes were obtained. These results suggested that the polymer backbones comprised not only linear moieties but also a large number of branching moieties. The results of run 11 listed in Table I indicated the possibility of a scale-up in the addition-condensation of 1a with formaldehyde.

Polymerization of 3-(trifluoromethoxy)benzyl Bromide (1b) or 4-(trifluoromethoxy)benzyl Bromide (1c) via FriedelCrafts Polymerization

The backbone of the phenolic resin [poly(phenylenemethylene)] can be constructed under formaldehyde-free conditions. One example of a simple method is the Friedel-Crafts polymerization of electron-rich halo-methylbenzene derivatives. The polymerization of 3-(trifluoromethoxy)benzyl bro- 


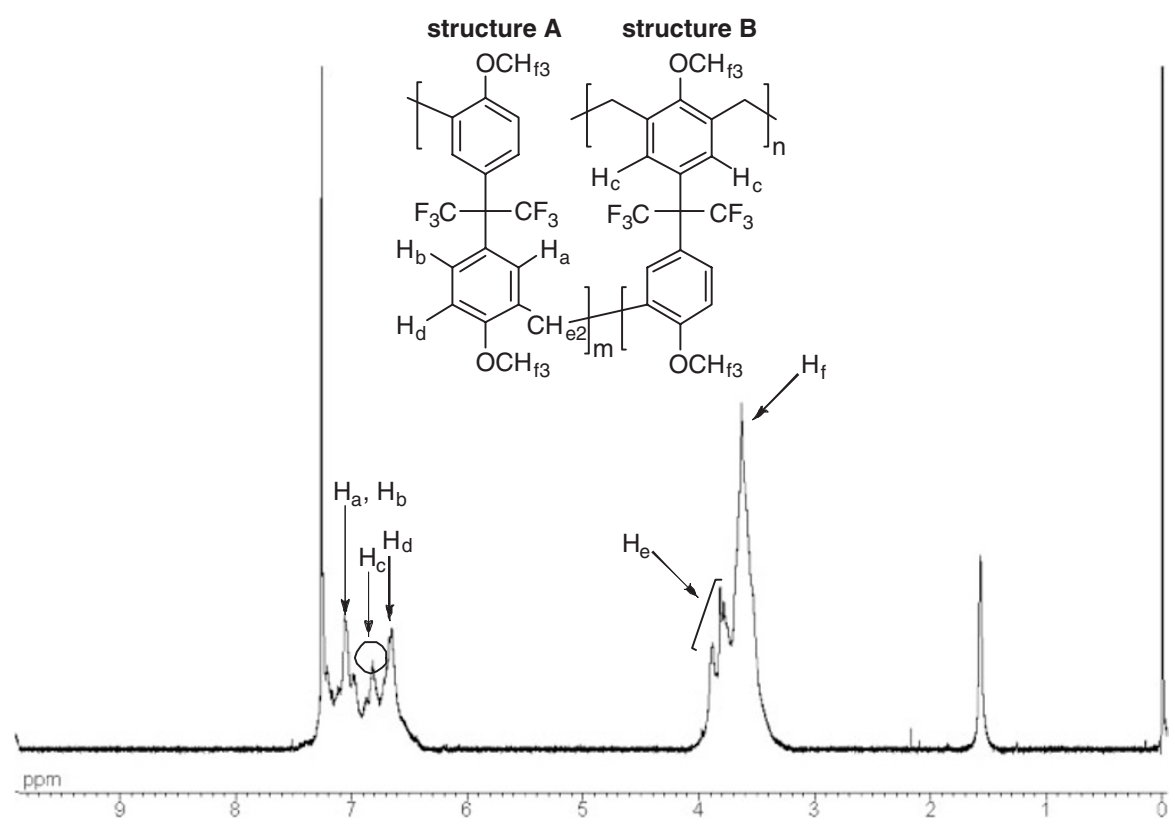

Figure 2. ${ }^{1} \mathrm{H}$ NMR spectrum of $\mathbf{2 a}$ in $\mathrm{CDCl}_{3}$.

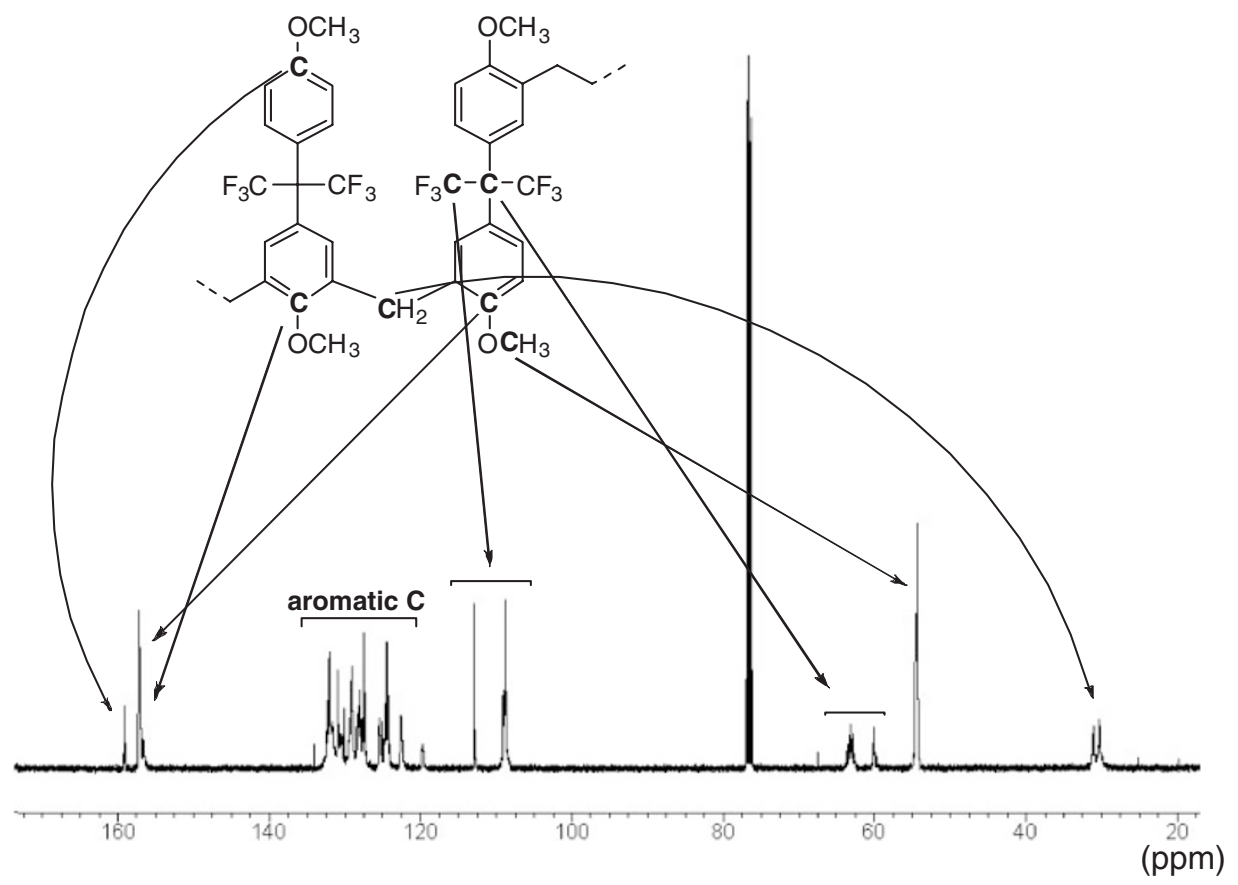

Figure 3. ${ }^{13} \mathrm{C}$ NMR spectrum of $\mathbf{2 a}$ in $\mathrm{CDCl}_{3}$.

mide (1b) or 4-(trifluoromethoxy)benzyl bromide (1c) was performed according to Scheme 2 and 3 (the typical methods are cited in the experimental section). When the polymerization of 1b was performed, an organosoluble polymer (2b) was obtained in $38 \%$ yield after reprecipitation with a large amount of methanol. The $M_{\mathrm{n}}$ and $M_{\mathrm{w}} / M_{\mathrm{n}}$ of $\mathbf{2 b}$ were estimated as 2800 and 3.1, respectively, from the GPC analysis. The FT-IR and ${ }^{1} \mathrm{H}$ NMR spectra revealed that $\mathbf{2 b}$ had arylene-methylene repeating units, i.e., this product was fluorine-containing poly(arylenemethylene).
On the other hand, when the polymerization of 1c was conducted, the product, which was soluble in organic solvents such as chloroform and THF, was obtained in $67 \%$ yield. However, the $M_{\mathrm{n}}$ and $M_{\mathrm{w}} / M_{\mathrm{n}}$ of the product were 850 and 1.4, respectively. This result indicated that $1 \mathrm{c}$ could be polymerized via the Friedel-Crafts polymerization; however, the molecular weight of the product was not so high because of the lower reactivity on the solution polymerization. To enhance the Friedel-Crafts alkylation reaction, the bulk polymerization of 1c was performed. After purification, the product $\mathbf{2 c}$ was 


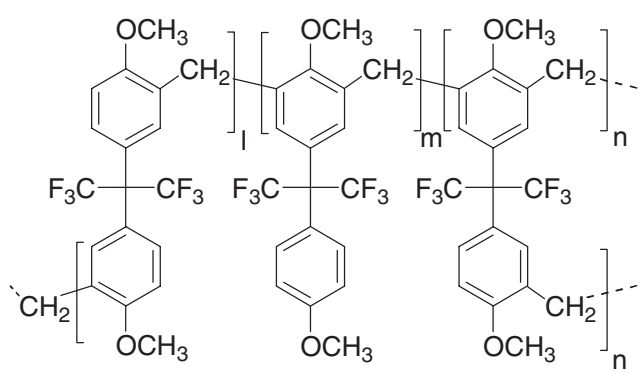

Figure 4. Prospective structure of $2 \mathrm{a}$ from ${ }^{1} \mathrm{H}$ and ${ }^{13} \mathrm{C}$ NMR spectra.

obtained in $16 \%$ yield. From the FT-IR spectrum, the peaks due to a benzene ring $\left(3040 \mathrm{~cm}^{-1}\right)$, a methylene unit $\left(2924 \mathrm{~cm}^{-1}\right)$, and a C-F bond $\left(1060 \mathrm{~cm}^{-1}\right)$ were confirmed. The ${ }^{1} \mathrm{H}$ NMR spectrum of $\mathbf{2 c}$ indicated that the peaks derived from the aromatic and methylene protons appeared at 7.8-7.6 and 7.2$6.5 \mathrm{ppm}$, and 4.1-3.5 ppm, respectively, as shown in Figure 5. The ${ }^{13} \mathrm{C}$ NMR spectrum also indicated that $2 \mathrm{c}$ had arylene- methylene-arylene units. From the GPC analysis, the $M_{\mathrm{n}}$ and $M_{\mathrm{w}} / M_{\mathrm{n}}$ of $\mathbf{2 c}$ were estimated to be 7100 and 2.8, respectively. These results indicated that $\mathbf{2 c}$ was a fluorine-containing poly(arylenemethylene). Thus, the polymer structure of $\mathbf{2 c}$ could be discussed on the basis of the ${ }^{1} \mathrm{H}$ and ${ }^{13} \mathrm{C}$ NMR spectra; however, it is difficult to calculate the ratio of the branched units or to identify the reactive sites on the benzene rings since the peaks due to the aromatic protons overlapped each other. Furthermore, in spite of the higher $M_{\mathrm{n}}$ of $\mathbf{2 c}$, the yield of the product in the bulk polymerization of $1 \mathbf{c}$ was considerably lower than that of the solution polymerization. This probably was a result of the reactivity of substrates on the surface of $\mathrm{AlCl}_{3}$ and the solubility of the product in the liquid phase of 1c. During the polymerization, the substrate around $\mathrm{AlCl}_{3}$ could be polymerized to form a high molecular weight polymer, but the catalyst $\mathrm{AlCl}_{3}$ was probably coated by a high viscosity polymer that interfered with the further polymerization of non-reacted or oligomeric substrates; therefore the yield of $\mathbf{2 c}$ was low despite the high molecular weight.

Table I. Addition-condensation of 2,2-bis(4-methoxyphenyl)hexafluoropropane (1a) with formaldehyde

\begin{tabular}{|c|c|c|c|c|c|c|c|c|}
\hline run & $\begin{array}{c}\text { feed ratio } \\
(\mathrm{mmol}) \\
\text { (1a: aldehyde) }\end{array}$ & $\begin{array}{l}\text { solvent } \\
(\mathrm{ml})\end{array}$ & $\begin{array}{c}\operatorname{acid}^{* 2} \\
(\mathrm{ml})\end{array}$ & $\begin{array}{l}\text { temp } \\
\left({ }^{\circ} \mathrm{C}\right)\end{array}$ & $\begin{array}{l}\text { time } \\
\text { (h) }\end{array}$ & $\begin{array}{c}\text { yield*3 }^{* 3} \\
(\%)\end{array}$ & $M_{\mathrm{n}}{ }^{* 6}$ & $M_{\mathrm{w}} / M_{\mathrm{n}}{ }^{* 6}$ \\
\hline 1 & $1: 1$ & TFA $^{* 1} 5$ & - & rt & 6 & 2.4 & 3800 & 1.1 \\
\hline 2 & $1: 1$ & TFA $2 / \mathrm{CHCl}_{3} 3$ & - & $\mathrm{rt}$ & 6 & N.D. $* 4$ & - & - \\
\hline 3 & $1: 1$ & TFA 5 & - & 50 & 6 & 65 & 2100 & 1.8 \\
\hline 4 & $1: 1$ & TFA $2 / \mathrm{CHCl}_{3} 3$ & - & 50 & 6 & N.D. $* 4$ & - & - \\
\hline 5 & $1: 1$ & TFA 5 & 0.2 & rt & 6 & 37 & 5300 & 1.6 \\
\hline 6 & $1: 1$ & TFA $2 / \mathrm{CHCl}_{3} 3$ & 0.2 & $\mathrm{rt}$ & 6 & 71 & 8200 & 2.1 \\
\hline 7 & $2: 2$ & TFA 2 & 0.4 & $\mathrm{rt}$ & 6 & N.D. ${ }^{* 5}$ & - & - \\
\hline 8 & $2: 2$ & TFA $0.8 / \mathrm{CHCl}_{3} 1.2$ & 0.4 & $\mathrm{rt}$ & 6 & N.D. ${ }^{* 5}$ & - & - \\
\hline 9 & $1: 1.5$ & TFA $2 / \mathrm{CHCl}_{3} 3$ & 0.2 & $\mathrm{rt}$ & 6 & 79 & $20000^{* 7}$ & $14.0^{* 7}$ \\
\hline 10 & $1: 2$ & TFA $2 / \mathrm{CHCl}_{3} 3$ & 0.2 & $\mathrm{rt}$ & 6 & 90 & $18300 * 7$ & $14.2^{* 7}$ \\
\hline 11 & $5: 5$ & TFA $8 / \mathrm{CHCl}_{3} 12$ & 1.0 & rt & 10 & 80 & 7400 & 2.0 \\
\hline
\end{tabular}

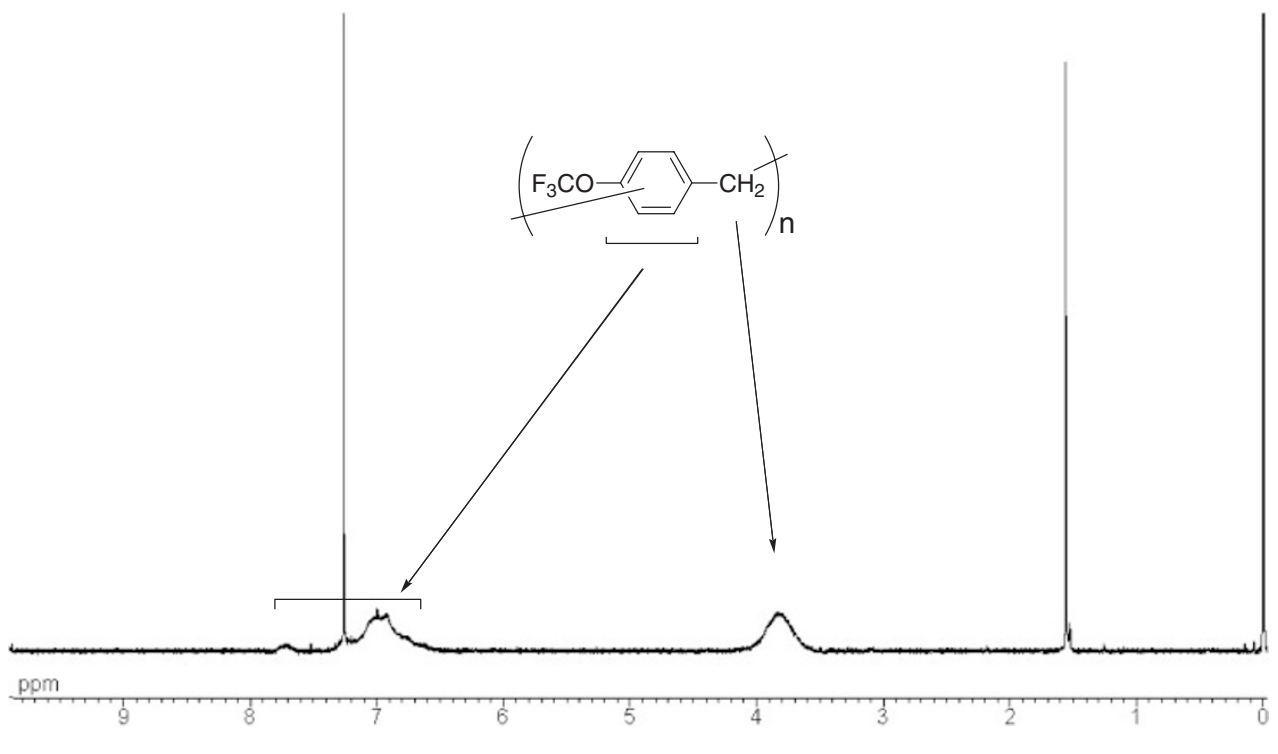

Figure 5. ${ }^{1} \mathrm{H}$ NMR spectrum of $\mathbf{2 c}$ in $\mathrm{CDCl}_{3}$. 


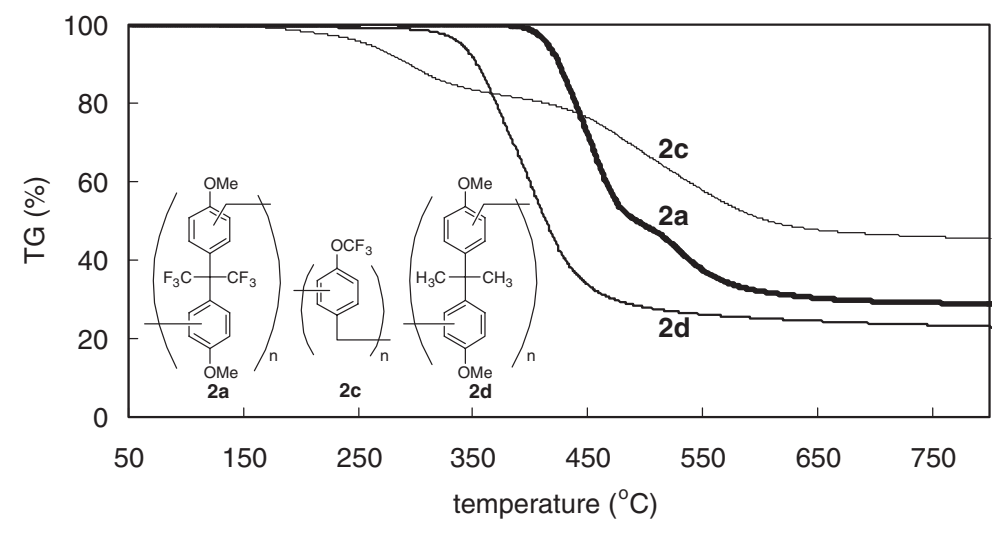

Figure 6. Thermogravimetric analyses of $\mathbf{2 a}, \mathbf{2 c}$ and $\mathbf{2 d}$ under a nitrogen atmosphere.

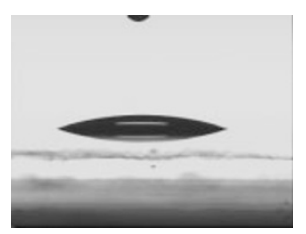

$2 \mathbf{a}\left(\theta=25.0^{\circ}\right)$

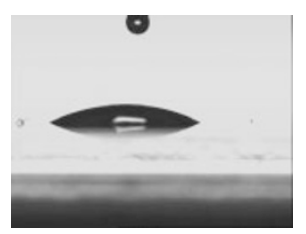

2c $\left(\theta=26.7^{\circ}\right)$

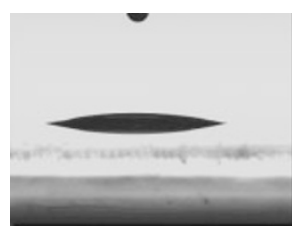

$2 \mathbf{d}\left(\theta=12.8^{\circ}\right)$

Figure 7. Contact angle of water droplet on the polymer thin film (2a, 2c, 2d).

\section{Thermal and Solution Properties of Polymers (2a, 2c)}

The thermal properties of the obtained polymers $(\mathbf{2 a}, \mathbf{2 c})$ were examined by thermogravimetric analyses (TGA) under a nitrogen atmosphere (Figure 6). To discuss the effect of the fluorine moieties, an organosoluble 2,2-bis(4-methoxyphenyl)propane-formaldehyde copolymer (2d) (Figure 6, inset) was prepared, ${ }^{8}$ and its $T_{10}$ (temperature at $10 \%$ loss in weight) was found to be $397^{\circ} \mathrm{C}$. For the 2,2-bis(4-methoxyphenyl)hexafluoropropane-formaldehyde copolymer (2a), the $T_{10}$ was found to be $425^{\circ} \mathrm{C}$ (an increase of $c a .30^{\circ} \mathrm{C}$ ). The result suggested that the thermal property of the polymer was enhanced by the introduction of the fluorine moieties; as a result, the fluorine-containing polymer 2a displayed a high thermal stability. The polymer $2 \mathrm{c}$ derived from 4-(trifluoromethoxy)benzyl bromide had a lower $T_{10}\left(298^{\circ} \mathrm{C}\right)$ than $2 \mathbf{a}$. These results suggested that the difference between the $T_{10}$ of $\mathbf{2 a}$ and 2c was due to the difference in the structures of the polymers. In the case of $\mathbf{2 a}$, a trifluoromethyl group was directly attached to the polymer backbone; hence, the introduction of fluorine resulted in the high thermal stability. On the other hand, $\mathbf{2 c}$ had an ether bond between the trifluoromethyl group and the polymer backbone. As shown in the conventional novolacs with alkoxy groups on the polymer backbone, the alkoxy groups were initially destroyed on TGA, so the low $T_{10}$ values might be dependent on the difference in the polymer structures.

The solution properties of $\mathbf{2 a}$ and $\mathbf{2} \mathbf{c}$ in a dilute THF solution were estimated by using an SEC-VISC-RALLS system (Viscotek). The samples (2a' and $\mathbf{2} \mathbf{c}^{\prime}$ ) used for the RALLS analysis, which were high-molecular-weight polymers, were separated from $\mathbf{2 a}$ and $\mathbf{2 c}$ by HPLC. In the case of $\mathbf{2} \mathbf{a}^{\prime}\left(M_{\mathrm{n}}\right.$ : $32000, M_{\mathrm{w}} / M_{\mathrm{n}}: 1.35$; RALLS), the parameters $a$ and $\log K$ of the Mark-Houwink-Sakurada equation $\left([\eta]=K \mathrm{M}^{a}\right)$ were 0.16 and -2.11 , respectively. For the polymer $2 \mathbf{c}^{\prime}\left(M_{\mathrm{n}} 50000\right.$, $\left.M_{\mathrm{w}} / M_{\mathrm{n}} 1.59 ; \mathrm{RALLS}\right), a$ and $\log K$ were 0.34 and -2.95 , respectively. These values of $a(0.16$ and 0.34$)$ are considerably less than those of a linear polymer ( $c a .0 .6-0.8$ ); therefore, the results indicated that $\mathbf{2 a}$ and $\mathbf{2 c}$ could have spherical structures with a compactly branched three-dimensional topology in dilute THF solutions. These polymers are probably hyperbranched polymers that are found in common phenol novolacs.

\section{Contact Angle Measurements}

The trifluoromethyl group is a component that can provide extremely low surface energy to a material's surface. The trifluoromethylated polymers, therefore, would have good water and oil repellency. The polymer's water repellencies were estimated by measuring the contact angles $(\theta)$ of water droplets with the polymer film surfaces ${ }^{7 \mathrm{~d}}$ (Figure 7). The contact angles of water droplets on the $\mathbf{2 a}$ and $\mathbf{2 c}$ polymer films were $25.0^{\circ}$ and $26.7^{\circ}$, respectively. A comparison with the contact angle of a water droplet on the polymer $2 \mathbf{d}\left(12.8^{\circ}\right)$, which is not a trifluoromethylated polymer, revealed better water repellency in the case of fluorine-containing polymers $\mathbf{2 a}$ and 2c. These fluorine-containing polymers were inferior to the popular fluorine-containing polymers such as Teflon in terms of the water repellency. This result indicated that trifluoromethyl moieties might be hidden by the surface of the polymer film; however, these polymers can be possibly used as additives for other fluorine-containing polymers. 


\section{CONCLUSION}

We have successfully prepared organosoluble fluorinecontaining poly(arylenemethylene)s via addition-condensation or Friedel-Crafts polymerization. The obtained polymers demonstrated good solubility in organic solvents. Further, the polymers, particularly $\mathbf{2 a}$, exhibited a high thermal stability as compared to the conventional non-fluorinated polymers comprising arylene-methylene units. The obtained polymers also exhibited film-forming properties and water repellency; hence, they can be used as coating materials, thermosetting polymers, and additives to the conventional fluorine-containing polymers in order to improve their physical properties.

Received: February 8, 2008 Accepted: March 25, 2008

Published: May 14, 2008

\section{REFERENCES}

1. A. Knop and L. A. Plato, "Phenolic Resins," Springer-Verlag, Berlin, 1985.

2. a) A. Matsumoto, K. Hasegawa, A. Fukuda, and K. Otsuki, J. Appl. Polym. Sci., 44, 1547 (1991).

b) J. Kadota, T. Fukuoka, H. Uyama, K. Hasegawa, and S. Kobayashi, Macromol. Rapid Commun., 25, 441 (2004).

c) T. Fukuoka, H. Uyama, and S. Kobayashi, Macromolecules, 36, 8213 (2003).

d) G. Pan, Z. Du, C. Zhang, C. Li, X. Yang, and H. Li, Polym. J., 39, 478 (2007).

e) G. Konishi, T. Kimura, and Y. Nakamoto, Macromol. Res., 15, 191 (2007).

f) K. Suzuki, H. Matsumoto, M. Minagawa, M. Kimura, and A. Tanioka, Polym. J., 39, 1128 (2007). g) R. Lin, L. Fang, X. Li, Y. Xi, S. Zhang, and P. Sun, Polym. J., 38, 178 (2006).

3. D.-M. Shin, N. Ozeki, Y. Nakamoto, and G. Konishi, Macromol. Res., 14, 255 (2006).

4. T. Nemoto, T. Ueno, M. Nishi, D.-M. Shin, Y. Nakamoto, and G. Konishi, Polym. J., 38, 1278 (2006).

5. a) T. Kimura, Y. Nakamoto, and G. Konishi, Polym. J., 38, 606 (2006).

b) J. Jeerupan, G. Konishi, T. Nemoto, D.-M. Shin, and Y. Nakamoto, Polym. J., 39, 762 (2007).

c) T. Nemoto and G. Konishi, submitted.

6. For related reports, see: a) H. Sawada, Polym. J., 39, 637 (2007).

b) Z. Tao, S. Yang, Z. Ge, J. Chen, and L. Fan, Eur. Polym. J., 43, 550 (2007).

c) T. Ishizone, K. Sugiyama, Y. Sakano, H. Mori, A. Hirao, and S. Nakahama, Polym. J., 31, 983 (1999).

d) H. Yokoyama, K. Tanaka, A. Takahara, T. Kajiyama, K. Sugiyama, and A. Hirao, Macromolecules, 37, 939 (2004).

e) T. Narita, J. Polym. Sci., Part A: Polym. Chem., 42, 4101 (2004).

f) K. Ohshimizu, Y. Shibasaki, and M. Ueda, Polym. J., 39, 777 (2007).

g) Z. Ge, Z. Tao, J. Liu, L. Fan, and S. Yang, Polym. J., 39, 1135 (2007).

h) M. Nasir, H. Matsumoto, M. Minagawa, A. Tanioka, T. Danno, and H. Horibe, Polym. J., 39, 670 (2007).

i) M. Nasir, H. Matsumoto, M. Minagawa, A. Tanioka, T. Danno, and H. Horibe, Polym. J., 39, 1060 (2007).

j) H. Masunaga, S. Sasaki, K. Tashiro, M. Hanesaka, M. Takata, L. Inoue, N. Ohta, and N. Yagi, Polym. J., 39, 1281 (2007).

k) K. Mikame and M. Funaoka, Polym. J., 38, 585 (2006).

7. a) C.-P. Yang, Y.-Y. Su, and M.-Y. Hsu, Polym. J., 38, 132 (2006).

b) Y. Watanabe, Y. Shibasaki, S. Ando, and M. Ueda, Polym. J., 38, 79 (2006).

c) Y. Hayakawa, N. Terasawa, and H. Sawada, Polymer, 42, 4081 (2001).

d) K. Li, P. Wu, and Z. Han, Polymer, 43, 4079 (2002).

e) M. Futamata, X. Gai, and H. Itoh, Vacuum, 73, 519 (2004).

8. 2d: unpublished results, $M_{\mathrm{n}} 8400, M_{\mathrm{w}} / M_{\mathrm{n}} 4.34$. 